Mat. Res. Bull., Vol. 27, pp. 1003-1008, 1992. Printed in the USA.

0025-5408/92 \$5.00 +.00 Copyright (c) 1992 Pergamon Press Ltd.

\title{
OPTICAL PROPERTIES OF ZINC OXIDE CLUSTERS ENCAPSULATED IN A ZEOLITE HOST
}

\begin{abstract}
Thomas Türk, Frank Sabin and Arnd Vogler* Universität Regensburg, Institut für Anorganische Chemie Universitätsstr. 31, D-8400 Regensburg, FRG
\end{abstract}

(Received March 20, 1992; Communicated by G. Blasse)

\section{ABSTRACT}

The optical properties of nanometer-sized semiconductor materials are of interest in areas such as photocatalysis and non-linear optics. Ultrasmall zinc oxide particles encapsulated in a porous zeolite (A) host were characterized by powder X-ray diffraction, reflectance, and luminescence spectra. Compared to bulk Zno the particles show pronounced blue shifts of the reflectance as well as the luminescence bands owing to the quantum size effect.

MATERIALS INDEX: zinc, oxide, zeolite

\section{INTRODUCTION}

The optical properties of $\mathrm{Zno}$ [1-3] and related materials $[4,5]$ have attracted much interest in recent years. Special attention has been paid to small zno particles which show the quantum size effect $[6,7]$. With decreasing size the band gap becomes larger and the absorption as well as the emission is shifted to shorter wavelength. Quantum mechanical calculations providing a predicted size dependence of the lowest excited state have been published by Brus [8].

Extremely small but chemically modified zno particles are accessible as well defined molecular clusters such as [ Zn4O(acetate)6] [9]. As an alternative ultrasmall semiconductor particles can be prepared by encapsulating them in zeolites. This method has been demostrated successfully for CdS, PbS $[10,11]$ or $\mathrm{M}_{4} \mathrm{X}^{6+}$ clusters $(\mathrm{M}=\mathrm{Zn}$ or $\mathrm{Cd}$ and $\mathrm{X}=\mathrm{S}$ or $\mathrm{Se})$ [12]. Zeolites are crystalline alumosilicates with pore sizes on the order of atomic dimensions and serve as hosts for the self assembly of small semiconductor moieties with well defined size and shape [13]. 
We report the synthesis of small zno clusters in the cavities of a zeolite $A$ and compare their optical properties with those of Zno bulk material $[2,7]$. The size of the encapsulated particles can not exceed $11 \dot{A}$ given by the diameter of the available zeolite $A$ cages [14]. Powder $X$-ray diffraction data of $\mathrm{Zno} / z e o l i t e \mathrm{~A}$ confirmed the assumption that $\mathrm{Zno}$ was indeed included in the alumosilicate host. Substantial blue-shifts of both the reflectance and emission spectra could be observed. Quenching experiments were carried out in order to verify the presence of $\mathrm{ZnO}$ in the zeolite cages.
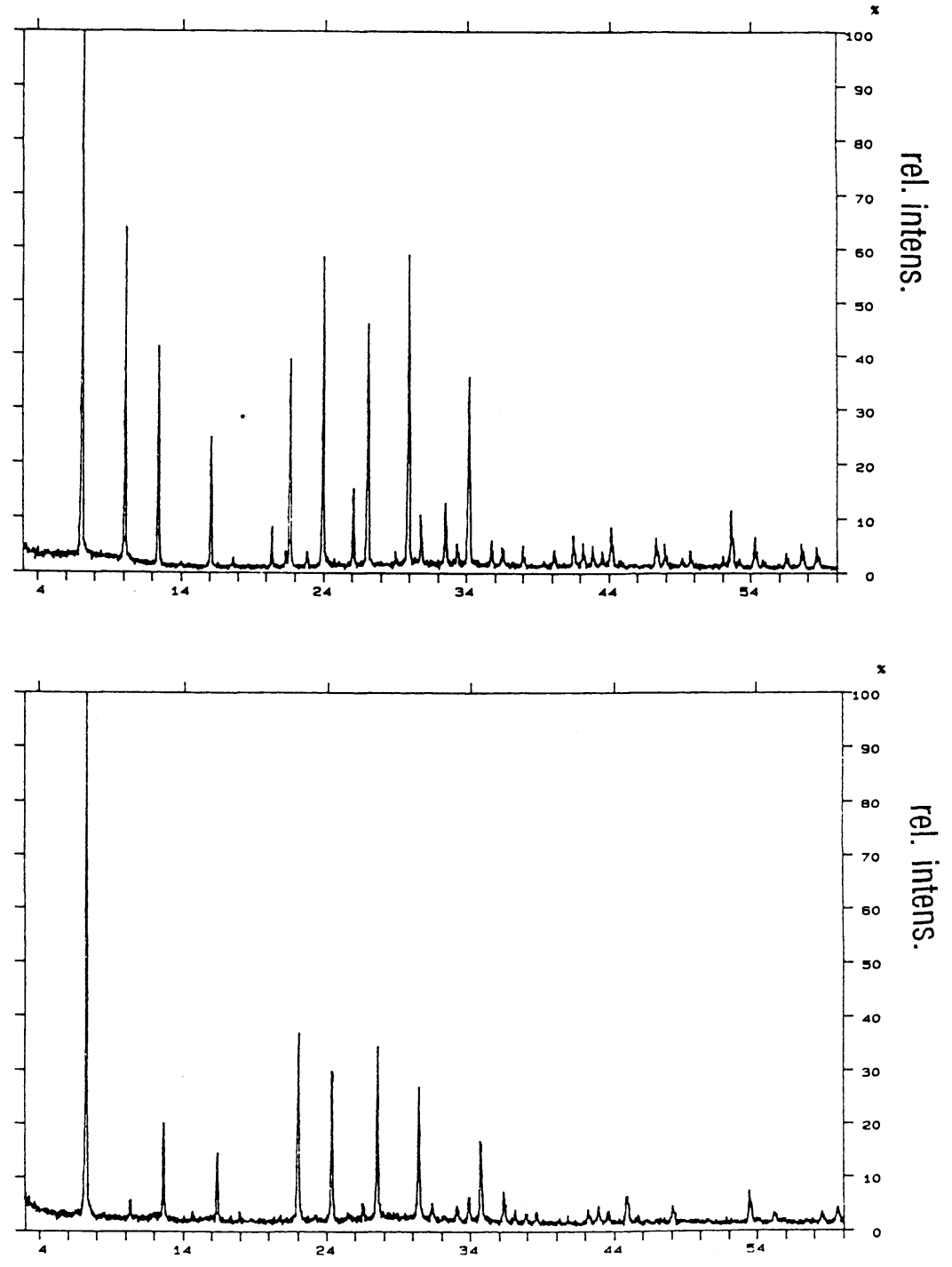

FIG.1

$\mathrm{X}$-ray powder diffractogramm profiles of zeolite $\mathrm{A}$ (upper) and Zno/zeolite A (lower). 


\section{EXPERIMENTAL}

A precursor of $\mathrm{Zno} / z e o l i t e \mathrm{~A}$ was synthesized by stirring a zeolite A (Degussa, Wessalith $\mathrm{P}$ ) suspension in water with $\mathrm{ZnCl} 2$ in order to exchange $\mathrm{Na}^{+}$for $\mathrm{Zn}^{2+}$ ions [15]. Subsequent heating ( $600{ }^{\circ} \mathrm{C}, 4$ hours) of the ion exchanged zeolite led directly to the formation of the small zno clusters within the zeolite cages as indicated by the changes of the powder X-ray diffraction patterns. This pattern would not change if $\mathrm{ZnO}$ is attached only to the surface of the zeolite. However, the zeolite peak intensities in the powder diffraction profile of Zno/zeolite $A$ were significantly different from those of the pure zeolite A (Fig. 1). Similar observations for CdS clusters in zeolites have been published [10].

The powder reflectance spectra of bulk Zno (Ventron, $99,9 \%)$ and Zno/Zeolite A were measured on a UV/VIS spectrometer from SHIMADZU (UV-2100) equipped with a reflexion accessory. Reference was BaSO4. The luminescence spectra of the powders were recorded with a HITACHI 850 fluorescence spectrophotometer and the high resolution powder diffraction data were collected using a SCINTAG $P A D x$ automated $x$-ray diffractometer using $C u$ $\mathrm{K} \alpha_{1}$ radiation.

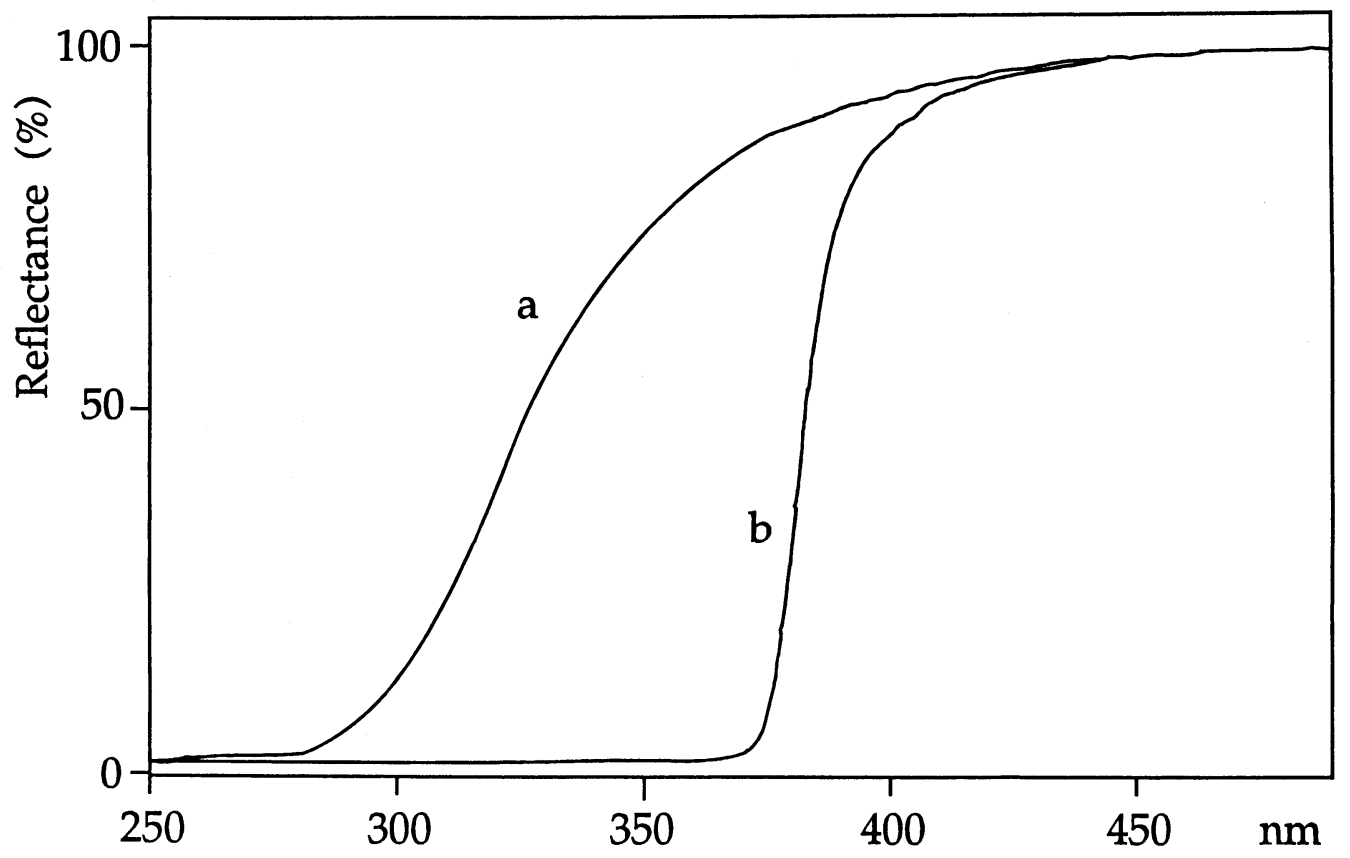

FIG. 2

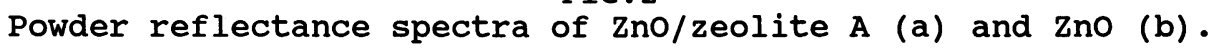




\section{RESULTS AND DISCUSSION}

The powder reflectance spectra of bulk $\mathrm{Zno}$ and $\mathrm{Zno} / \mathrm{zeolite}$ $A$ are given in Fig. 2. While bulk zno powder with a band gap energy of $3.2 \mathrm{eV}$ [16] showes complete light absorption below $370 \mathrm{~nm} \mathrm{Zno} / z$ eolite $\mathrm{A}$ does not reflect any light below $280 \mathrm{~nm}$. The pure alumosilicate did not display a remarkable absorption above $200 \mathrm{~nm}$. For ultrasmall zno particles (particle size approximately $10 \mathrm{~A}$ ) prepared in methanolic solutions an absorption onset of $260 \mathrm{~nm}$ has been reported [1].

Bulk Zno is known for exhibiting two different types of luminescence [7]. The short wavelength emission is ascribed to the band gap recombination of electron and hole while the visible emission is assumed to have its origin in recombining surface trapped electrons [2]. This emissions of zinc oxide powder appear at $\lambda_{\max }=383 \mathrm{~nm}$ and $518 \mathrm{~nm}$, respectively (Fig. 3). The Zno/zeolite A powder spectrum displays maxima at $373 \mathrm{~nm}$ and $400 \mathrm{~nm}$ (Fig. 3). The shorter wavelength maximum is assigned to the band gap emission of the encapsulated zno particles. Owing to the quantum size effect the luminescence is blueshifted compared to bulk $\mathrm{ZnO}$. The origin of the longer wave-

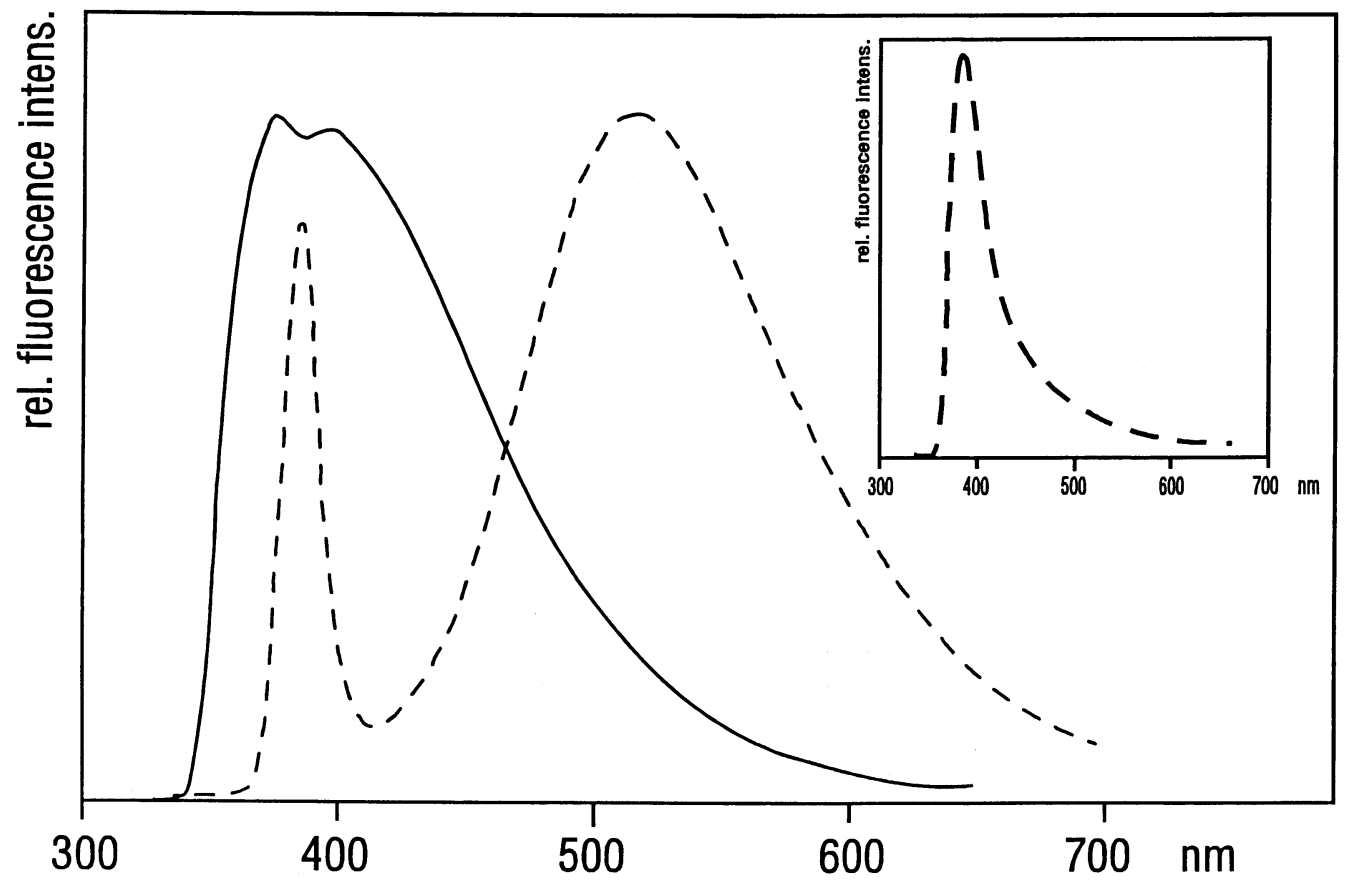

FIG. 3

Emission spectra from powders of Zno/zeolite A (solid line) and Zno (dashed line). Inset: Emission spectrum of a Zno suspension in water. Concentration of $\mathrm{Cu}^{2+}$ was $0.5 \mathrm{M}$. Excitation at $280 \mathrm{~nm}$. 
lengh luminescence is less clear since the particle size of $\mathrm{Zno}$ in the zeolite is of molecular dimensions. In this case, the existence of surface states is questionable. However, a luminescence of $\mathrm{ZnO}$ suspensions in 2-propanol at $\lambda_{\max }=460 \mathrm{~nm}$ was reported for particle sizes below the detection limit of the transition electron microscope (approximately 5 A) [2]. This emission was assigned to surface states. Furthermore, the visible luminescence of $\mathrm{Cd}_{4} \mathrm{~S}_{4}$ units encapsulated in zeolites is assumed to arise from cd related defects rather than from a band gap recombination [17]. Accordingly, we suggest that the $400 \mathrm{~nm}$ emission of Zno/zeolite A has a similar origin. This assumption is supported by quenching experiments.

$\mathrm{Cu}^{2+}$ ions are well known as efficient quenchers of the visible luminescence of aqueous zno colloids [7]. The inset of Fig. 3 gives the emission spectrum of bulk zno suspended in a concentrated solution of $\mathrm{Cu}^{2+}$. While the broad luminescence of zinc oxide at $518 \mathrm{~nm}$ is quenched almost completely $\mathrm{Cu}^{2+}$ ions have no influence on the $400 \mathrm{~nm}$ band of $\mathrm{Zno} / \mathrm{zeolite} \mathrm{A}$. The access to the zeolite $A$ cages is only possible for ions smaller $4.1 \dot{A}[14]$. However, for hydrated $\mathrm{Cu}^{2+}$ ions diameters of approximately $7 \mathrm{~A}$ are reported in literature [18]. Thus, quenching of the visible luminescence of the encapsulated zno particles should not occur in accord with our observations.

\section{CONCLUSIONS}

Nano-sized Zno clusters were encapsulated in the cages of a zeolite host. The optical properties such as absorption and luminescence showed the quantum-size effect. The band gap transition was blue shifted when compared to bulk Zno. The new material belongs to a class of compounds which are of general interest in areas such as photocatalysis and non-linear optics.

\section{ACKNOWLEDGMENT}

We thank M. Vitale and Dr. M. Zabel for help with the Xray measurements. This work was supported by the Deutsche Forschungsgemeinschaft.

\section{REFERENCES}

[1] M. Haase, H. Weller and A. Henglein, J. Phys Chem., 92, 482 (1988).

[2] D. Bahnemann, C. Kormann and M.R. Hoffmann, J. Phys. Chem., 91, 3789 (1987).

[3] B. Andress, Zeitschrift für Physik, 170, 1 (1962).

[4] G. Blasse, Chem. Phys. Letters, 175, 237 (1990).

[5] A. Meijerink, G. Blasse and M. Glasbeek, J. Phys.: Condens. Matter, 2,6303 (1990).

[6] U. Koch, A. Fojtik, H. Weller and A. Henglein, Chem. Phys. Let., 122, 507 (1985). 
[7] A. Henglein, Top. Curr. Chem., 143, 113 (1988).

[8] M.L. Steigerwald and L.E. Brus, Acc. Chem. Res., 23, 183 (1990).

[9] H. Kunkely and A. Vogler, J. Chem. Soc., Chem. Commun., 1204 (1990).

[10] N. Herron, Y. Wang, M.M. Eddy, G.D. Stucky, D.E. Cox, K. Moller and T. Bein, J. Am. Chem. Soc., 111, 530 (1989).

[11] Y. Wang and N. Herron, J. Phys. Chem., 95, 525 (1991).

[12] K.L. Moran, W.T.A. Harrison, T.E. Gier, J.E. Mac Dougall and G.D. Stucky, Mat. Res. Soc. Symp. Proc., 123 (1990).

[13] G.D. Stucky and J.E. Mac Dougall, Science, 247, 669 (1990).

[14] D.W. Breck, W.G. Eversole, R.M. Milton, T.B. Reed, and T.L. Thomas, J. Am. Chem. Soc., 78, 5963 (1956).

[15] F. Wolf and H. Fürtig, Kolloid Z. Z. Polymere, 206, 48 (1965).

[16] M.A. Fox, ACC. Chem. Res., 16, 314 (1983).

[17] N. Herron, ACS Symp. Ser., $\underline{455}, 582$ (1991).

[18] M.J. Quintin, Chim. Phys., 3․ 433 (1936). 